\title{
Molecular Etiology of Primary Hyperoxaluria Type 1: New Directions for Treatment
}

\author{
Christopher J. Danpure \\ Department of Biology, University College London, London, UK
}

\author{
Key Words \\ Primary hyperoxaluria type $1 \cdot$ Alanine:glyoxylate \\ aminotransferase - AGXT • Liver transplantation . \\ Enzyme replacement therapy - Pyridoxine · \\ Gene therapy - Chemical chaperones - Kidney stones · \\ Calcium oxalate
}

\begin{abstract}
Primary hyperoxaluria type $1(\mathrm{PH} 1)$ is a rare autosomalrecessive disorder caused by a deficiency of the liver-specific enzyme alanine:glyoxylate aminotransferase (AGT). AGT deficiency results in increased synthesis and excretion of the metabolic end-product oxalate and deposition of insoluble calcium oxalate in the kidney and urinary tract. Classic treatments for $\mathrm{PH} 1$ have tended to address the more distal aspects of the disease process (i.e. the symptoms rather than the causes). However, advances in the understanding of the molecular etiology of $\mathrm{PH} 1$ over the past decade have shifted attention towards the more proximal aspects of the disease process (i.e. the causes rather than the symptoms). The determination of the crystal structure of AGT has enabled the effects of some of the most important missense mutations in the AGXT gene to be rationalised in terms of AGT folding, dimerization and stability. This has opened up new possibilities for the design pharmacological agents that might counteract the destabilizing effects of these mutations and which might be of use for the treatment of a potentially life-threatening and difficult-to-treat disease.
\end{abstract}

Copyright ( $\odot 2005$ S. Karger AG, Basel (c) 2005 S. Karger AG, Basel 0250-8095/05/0253-0303\$22.00/0

Fax +4161306 1234 E-Mail karger@karger.ch www.karger.com www.karger.com/ajn

\section{Molecular Etiology of PH1}

\section{PH1 and AGT Deficiency}

Primary hyperoxaluria type 1 ( $\mathrm{PH} 1, \mathrm{MIM} 259900)$ is a rare autosomal-recessive disorder caused by a deficiency of the liver-specific pyridoxal-phosphate-dependent enzyme alanine:glyoxylate aminotransferase (AGT, EC 2.6.1.44) [1]. AGT catalyses the transamination of the intermediary metabolite glyoxylate to glycine, but its deficiency in PH1 allows glyoxylate to be reduced to glycolate and oxidised to oxalate instead. Although glycolate can be further metabolised, oxalate cannot and can only be removed from the body by renal excretion. The resulting hyperoxaluria usually, but not always, accompanied by hyperglycolic aciduria are the hallmarks of PH1. Most of the pathology associated with $\mathrm{PH} 1$ is caused by the low solubility of calcium oxalate $(\mathrm{CaOx})$. Over time, insoluble $\mathrm{CaOx}$ is deposited in the kidney and urinary tract as nephrocalcinosis and/or urolithiasis. More often than not this leads to renal failure, at which point the elevated synthesis of oxalate is compounded by the failure to remove it from the body. The resulting high corporeal oxalate load leads to $\mathrm{CaOx}$ deposition almost anywhere throughout the body $[2,3]$.

\section{Enzyme Heterogeneity}

A number of different enzyme phenotypes have been identified in PH1. Some patients have a complete, or nearly complete, absence of AGT immunoreactivity and catalytic activity (CRM-/ENZ-), while others have nor-
Professor Christopher J. Danpure

Department of Biology, University College London

Gower Street

London WC1E 6BT (UK)

Tel./Fax +44 207679 7936, E-Mail c.danpure@ucl.ac.uk 
mal, or near normal, levels of AGT immunoreactivity but almost no catalytic activity (CRM+/ENZ-). Yet other patients, totalling about one third of the total, have significant levels of both AGT immunoreactivity and catalytic activity (CRM+/ENZ+) [4].

Each of these crude categorizations of enzyme phenotype can be related to specific functional abnormalities of AGT at the molecular and cell biological levels. For example, in CRM-/ENZ- patients, either no AGT protein is synthesised or if it is then it is very rapidly degraded. In CRM+/ENZ- patients, AGT fails to bind its cofactor pyridoxal phosphate [5]. In CRM+/ENZ+ patients, disease is due to a remarkable trafficking defect in which AGT is mistargeted from its normal location in the peroxisomes to the mitochondria [6]. Intermediate enzyme phenotypes also exist. For example, in some CRM \pm / ENZ- patients, AGT is aggregated into peroxisomal cores [7].

\section{AGT Structure}

AGT is a homodimeric protein, each subunit possessing 392 amino acids and molecular mass of about $43 \mathrm{kDa}$ [8]. The X-ray crystal structure of normal AGT has been solved to a resolution of $2.5 \AA$ (PDB 1H0C) [9]. AGT forms an intimate dimer each subunit of which is comprised of three structural domains. The first 20 or so residues make up an N-terminal extension that wraps over the surface of the other subunit. The next 260 or so residues form the 'large domain' that contains most of the active site and the dimerization interface. The final Cterminal 'small domain' consists of about 110 residues and contains, among other things, the principal and ancillary peroxisomal targeting information $[10,11]$. Each subunit binds one pyridoxal phosphate which forms a Schiff base with Lys209. The large surface area of the dimerization interface explains the high stability of the AGT dimer. Although the interaction of the N-terminal extension of one subunit with the surface of the other subunit is unlikely to make any major contribution to stability to the dimer once formed, it is believed to play a significant role in the dimerization process per se. Dimerization is very important, not only because evidence suggests that monomeric AGT has vastly reduced catalytic activity [5], but also because it is unstable leading to aggregation and rapid degradation [7]. Knowledge of the crystal structure of AGT not only provides insights into the processes of AGT folding, dimerization and catalytic activity, but also helps us understand the effects of mutations and polymorphisms on these processes (see below).

\section{Effects of Mutations and Polymorphisms on the \\ Properties of $A G T$}

AGT is encoded by the $A G X T$ gene which is located on chromosome $2 \mathrm{q} 37.3$ and is comprised of 11 exons spreading over $10 \mathrm{kB}$ [12]. Two main polymorphic variants have been identified in European and North American populations. The 'minor' allele differs from the 'major' allele by the presence of $32 \mathrm{C} \rightarrow \mathrm{T}$ and $1020 \mathrm{~A} \rightarrow \mathrm{G}$ nucleotide substitutions, which lead to Prol1Leu and Ile340Met amino acid replacements, respectively [13]. In addition, the minor $A G X T$ allele contains a 74-bp duplication in intron 1 [14]. Unlike most polymorphisms in most genes, the Pro11Leu replacement does have significant affects on the properties of AGT. For example, it decreases its specific catalytic activity by two thirds, slows down the rate of AGT dimerization, especially at elevated temperatures [5], and it redirects a small proportion (about 5\%) away from the peroxisomes towards the mitochondria [13]. None of these effects appears to be too detrimental, as the presence of the polymorphism does not lead to any obvious adverse clinical phenotype. However, it does play an important role in $\mathrm{PH} 1$, because its presence appears to sensitise AGT to the adverse effects of a number of missense mutations, including the two most common ones, which are predicted to have no phenotype in the absence of the polymorphism [5].

Over 50 different mutations have been identified so far in the $A G X T$ gene, ranging from missense and nonsense point mutations, deletions, insertions, and splicesite variants [15]. Many of these mutations segregate with a specific polymorphic allele, and those that segregate with the minor $A G X T$ allele have their effects significantly affected by the presence of the Pro11Leu polymorphism [5]. The effects on enzyme function of only a few of these mutations have been characterized in any detail. The best studied are described below and summarized in table 1.

Gly170Arg. The most common mutation found so far is a $508 \mathrm{G} \rightarrow \mathrm{A}$ missense point substitution which leads to a Gly170Arg amino acid replacement [13]. This has an estimated allelic frequency of about $30 \%$ in unclassified European and North American PH1 patients. This mutation has little or no effect on the properties of AGT when present on its own. However, when located on the minor allele (i.e. with the Pro11Leu polymorphism), the two interact synergistically to delay AGT dimerization $[5,16]$ and redirect $90 \%$ of the enzyme away from its normal location in the peroxisomes to the mitochondria $[6,13$, 17]. Although still catalytically active, mistargeted AGT is metabolically inefficient. The Prol1 is located in the 
Table 1. Effect of mutations and polymorphisms on the properties of AGT

\begin{tabular}{|c|c|c|c|c|c|}
\hline $\begin{array}{l}\text { Nucleotide } \\
\text { change }\end{array}$ & $\begin{array}{l}\text { Amino acid } \\
\text { change }\end{array}$ & $\begin{array}{l}\text { Allelic } \\
\text { frequency } \\
\text { in PH1 }\end{array}$ & $\begin{array}{l}\text { Associated } \\
\text { polymorphic } \\
\text { allele }\end{array}$ & $\begin{array}{l}\text { Effect on AGT properties } \\
\text { (on appropriate polymorphic background })^{1}\end{array}$ & $\begin{array}{l}\text { Likely success } \\
\text { of chemical } \\
\text { chaperones }^{3}\end{array}$ \\
\hline \multicolumn{6}{|c|}{ PH1-specific mutations } \\
\hline $508 \mathrm{G} \rightarrow \mathrm{A}$ & Gly170Arg & $30 \%$ & minor & $\begin{array}{l}\text { dimerization inhibited, } 90-95 \% \text { mistargeted } \\
\text { from peroxisomes to mitochondria }\end{array}$ & good \\
\hline 33_34insC & - & $13 \%$ & major & correct polypeptide not synthesized & zero \\
\hline $731 \mathrm{~T} \rightarrow \mathrm{C}$ & Ile244Thr & $9 \%$ & minor & aggregates, degradation accelerated & good \\
\hline $121 \mathrm{G} \rightarrow \mathrm{A}$ & Gly41Arg & $1 \%$ & minor/major & $\begin{array}{l}\text { dimerization inhibited, aggregates in peroxisomes, } \\
\text { degradation accelerated }\end{array}$ & poor \\
\hline $245 \mathrm{G} \rightarrow \mathrm{A}$ & Gly82Glu & $1 \%$ & major & cofactor binding blocked & zero \\
\hline $613 \mathrm{~T} \rightarrow \mathrm{C}$ & Ser205Pro & $? \%$ & major & degradation accelerated & good \\
\hline \multicolumn{6}{|c|}{ Minor allele polymorphisms } \\
\hline $32 \mathrm{C} \rightarrow \mathrm{T}$ & Pro11Leu & $50 \%$ & [minor] & $\begin{array}{l}\text { specific activity decreased by two thirds, dimerization } \\
\text { slowed, } 5 \% \text { mistargeted from peroxisomes to mitochondria }{ }^{2}\end{array}$ & good \\
\hline $1020 \mathrm{~A} \rightarrow \mathrm{G}$ & Ile340Met & $50 \%$ & [minor] & no effect & N/A \\
\hline
\end{tabular}

middle of the N-terminal extension [9]. Its replacement by Leu generates a functionally weak mitochondrial targeting sequence (MTS), the efficiency of which is enhanced by the Gly170Arg replacement [18]. This is because the two together slow down the rate of AGT folding and dimerization $[5,16]$. This unparalleled explanation for a human genetic disease highlights one of the main differences between the peroxisomal and mitochondrial protein import pathways. Whereas peroxisomes can import fully folded cofactor-bound functionally active oligomeric proteins $[19,20]$, mitochondria can only import unfolded, or loosely folded, monomers [21, 22].

The locations of Pro11 and Gly170 in the crystal structure of AGT suggest a possible mechanism by which they might functionally interact. The Pro11Leu replacement allows the $\mathrm{N}$-terminal extension to adopt a conformation typical of a mitochondrial targeting sequence (MTS) [13, $17,18]$. However, it cannot work efficiently because AGT still dimerizes rapidly (albeit somewhat slower than when the polymorphism is absent), so that the N-terminal extension (now a cryptic MTS) still remains partially tethered to the surface of the opposing subunit. The additional presence of the Gly170Arg replacement delays dimerization further, so that the N-terminal extension cannot interact with the surface of the opposing subunit and is then free to interact with the mitochondrial import receptor TOM20 [23, 24]. Because mitochondrial import seems to exert a hierarchical dominance over peroxisomal import [25], AGT is redirected away from the peroxisomes towards the mitochondria.

Ile244Thr. The second most common missense mutation is a $731 \mathrm{~T} \rightarrow \mathrm{C}$ nucleotide substitution which encodes for a Ile244Thr amino acid replacement [26]. This has an overall allelic frequency of about $9 \%$ in PH1 patients. This mutation also works synergistically with the Pro11Leu polymorphism to give massively reduced AGT immunoreactivity and catalytic activity, presumably due to accelerated AGT degradation. In vitro studies have shown that the combined presence of the Pro11Leu and Ile244Thr replacements leads to AGT aggregation [27], although this has not been detected in patients. Analysis of the crystal structure of AGT gives little in the way of clues about how these replacements might achieve their effects on AGT. It is possible that they work similarly to the Pro11Leu+Gly170Arg combination as they would also be expected to interfere with the inter-subunit tethering of the N-terminal extension [9]. For reasons that are not understood, although Pro11Leu+Ile244Thr also inhibits AGT dimerization, they do not cause mistargeting to mitochondria.

Gly82Glu. All other missense mutations in the $A G X T$ gene are much rarer than Gly170Arg and Ile244Thr, and have been found in only a limited number of families. The $245 \mathrm{G} \rightarrow$ A substitution, which leads to a Gly82Glu 
Table 2. AGT-specific therapeutic procedures in $\mathrm{PH} 1$

\begin{tabular}{|c|c|c|c|}
\hline Therapeutic procedure & Mechanism of action & Mutational applicability & Timescale \\
\hline $\begin{array}{l}\text { Enzyme replacement therapy } \\
\quad \text { (liver transplantation) }\end{array}$ & replaces defective enzyme & all mutations & current \\
\hline Pyridoxine & $\begin{array}{l}\text { increases conversion of apo-enzyme to } \\
\text { holo-enzyme, stabilizes holo-enzyme (?) }\end{array}$ & Gly170Arg only (?) & current \\
\hline Gene therapy & replaces defective gene & all mutations & future (?) \\
\hline Chemical chaperones & stabilises defective protein & $\begin{array}{l}\text { many (but not all) } \\
\text { missense mutations }\end{array}$ & future (?) \\
\hline
\end{tabular}

replacement, has only been found only on the major $A G X T$ allele (i.e. without the Pro11Leu polymorphism) [28]. Patients homozygous for Gly82Glu are characterized by normal levels of correctly targeted AGT, but zero catalytic activity. Structural analysis shows that the reason for this is because, when glycine is replaced by glutamate, the side-chain of the latter blocks the pyridoxal phosphate binding site $[5,9]$. Because cofactor binding to Lys209 is essential for the normal catalytic cycle, the resulting enzyme has no catalytic activity.

Gly41Arg. The $121 \mathrm{G} \rightarrow$ A substitution, which leads to a Gly41Arg replacement, has been found on both the minor and major $A G X T$ alleles [7, 29]. Some evidence suggests that disease might be more severe when present on the former rather than the latter. In the presence of Pro11Leu, this mutation results in significant diminution of immunoreactive AGT, presumably due to accelerated degradation. The small amount of immunoreactive AGT remaining is without catalytic activity and appears to be aggregated into intra-peroxisomal cores [7]. Some AGT is also present in the mitochondria, but whether this is greater than the amount of mitochondrial AGT found in normal individuals homozygous for the minor allele is unclear. Structural analysis shows that Gly41 is located right in the middle of the dimerization interface in very close proximity to its opposite number in the other subunit [9]. If glycine were to be replaced by arginine, then the large side chain of the latter would prevent the apposition of the dimerization interfaces, thereby preventing dimerization. The intrinsic instability of the monomer would lead to its aggregation and accelerated degradation.

Ser205Pro. Ser205Pro is a rare mutation identified in a Japanese PH1 patient [30]. It is found on the major $A G X T$ allele. This mutation results in accelerated degradation so that patients in which it is found are CRM-/ ENZ- [31]. Structural analysis suggests that the replace- ment of serine by proline at this site would necessitate a large conformational change in the backbone of one of the $\beta$-strands of AGT that would completely disrupt the main chain hydrogen bonding of the central $\beta$-sheet [9]. This would make AGT highly unstable and lead to its rapid degradation.

33_34C. The second most common mutation is the 33_34CinsC insertion, which has an overall allelic frequency of about $13 \%$ in $\mathrm{PH} 1$ patients [15]. Patients homozygous for this mutation have no AGT immunoreactivity or catalytic activity. This is unsurprising and requires no knowledge of the structure of AGT to understand. This insertion causes a frame shift, so that the coding for AGT is lost and the protein cannot be made.

\section{New Directions for Treatment}

PH1 has been known about, and treated with varying degrees of success, for eighty years. Absence of any understanding of the molecular etiology of the disease meant that many treatments were introduced on a trial-and-error basis and dealt mainly with the later stages of the disease process. Little progress was made until 1986 when the basic cause of the disease (i.e. AGT deficiency) was discovered. Since then there have been enormous changes to all aspects of the clinical management of PH1. Some of the most important advances have been concerned with treatment (table 2).

\section{Classic Treatments}

The classic treatments for PH1 (i.e. those that we in use before the mid-1980s) involved decreasing the solubility product of $\mathrm{CaOx}$ in the urine, decreasing the chances of crystallization, crystal growth and crystal adherence to the tubule or collecting duct wall, and reacting to the effects of kidney failure (i.e. dialysis and kidney trans- 
plantation). Most of these approaches to treatment are still in use today, to one extent or another. Although potentially lifesaving, at least in the short term, these treatments at best slow down the rate of disease progression, rather than cure it. This is because they do not tackle the basic defect (i.e. hepatic AGT deficiency). Kidney transplantation, especially, is problematic because even though the new kidney may very well provide an immediate solution to the problem of kidney failure, it is highly likely to succumb to the ravages of $\mathrm{CaOx}$ deposition, as did the original organ.

\section{Pyridoxine Therapy}

One classic treatment that, in retrospect, probably did address the basic cause of the disease was pyridoxine treatment. For reasons that are not at all clear, pyridoxine therapy was introduced as a treatment for PH1 long before AGT deficiency was discovered. Whatever the reason, it has been well-recognised for many years that pharmacological doses of pyridoxine can be very effective at arresting disease progression in $10-30 \%$ of patients (reviewed in [2]). Pyridoxine (vitamin $\mathrm{B}_{6}$ ) is metabolised to pyridoxal phosphate (PLP) in the body, and PLP is the essential cofactor of AGT, as it is for all aminotransferases. Despite this knowledge, it is not at all clear how pyridoxine actually works in these responsive $\mathrm{PH} 1 \mathrm{pa}-$ tients.

It was noticed some time ago that patients were more likely to be responsive to pyridoxine treatment if they had significant levels of residual AGT (i.e. they were CRM+/ ENZ+) [2, 32]. As these patients, in general, have the Gly170Arg mutation and mitochondrial AGT, it followed that patients with mistargeted AGT were the ones responsive to pyridoxine. Formal evidence in support of this has come recently from a retrospective analysis of PH1 patients at the Mayo Clinic in Rochester, Minn., USA [33]. This study showed that pyridoxine responsiveness was clearly related to the presence of the Gly170Arg mutation. In general, patients homozygous for Gly $170 \mathrm{Arg}$ were more responsive than those expressing only one Gly170Arg allele.

What is clear is that pyridoxine exerts its effects on oxalate synthesis due to its effects on AGT. What is uncertain, however, is how it does it. The answer may not be known until a liver biopsy from a PH1 patient is analysed for AGT catalytic activity, immunoreactivity, and subcellular distribution, before and after pyridoxine treatment. As AGT mistargeting is thought to be due, at least in part, to a decrease in protein stability (see above), one possibility is that high concentrations of PLP stabilise
AGT and correct its targeting. Although many cofactors are known to stabilise the proteins with which they interact, there is no evidence of this happening with PLP and AGT. In fact the only evidence so far suggests that neither PLP nor pyridoxine can correct AGT targeting in an in vitro tissue culture system [34]. A significant proportion of the enzyme in normal liver might exist in the inactive apo form [35]. Large concentrations of PLP would be expected to shift the equilibrium away from the apo form towards the catalytically active holo form. The resulting increase in the specific activity of AGT could explain the beneficial effects of pyridoxine therapy. Presumably it would be the $5-10 \%$ of the AGT remaining in the peroxisomes which would be the most important in this respect, but increasing the activity in the mitochondria might also be beneficial. Another possibility is that increased intracellular levels of PLP might have a direct effect on the total amount of AGT protein in hepatocytes, either by increasing its rate of synthesis or decreasing its rate of degradation [35].

\section{Enzyme Replacement Therapy by Liver \\ Transplantation}

Identification of the defective enzyme in a metabolic disease often opens up the possibility of enzyme replacement therapy (ERT). This usually involves the purification of large amounts of enzyme, either isolated from a natural source or following production of recombinant protein, and then injection of the purified enzyme at regular intervals. This is best exemplified by lysosomal storage disorders, such as Gaucher disease (for a review see Beutler and Grabowski [36]). For these diseases, the enzyme is taken up by endocytosis. The endosomes fuse with lysosomes, so that the enzyme enters into the compartment where it is required to work (i.e. the lysosomes). Unfortunately, such an option is not available for peroxisomal diseases, such as PH1. Inside hepatocytes, AGT is located in the peroxisomes, an organelle that does not interact with endosomes or have any other interaction with the extracellular space. So that AGT taken into the cell will not be able to reach the necessary compartment (i.e. the peroxisomes), but instead would probably also make its way to the lysosomes where it would be degraded.

In humans, the vast majority of the body's AGT is located in liver parenchymal cells (i.e. hepatocytes) [3739], opening up the possibility that liver transplantation could be used as a form of ERT. Such a procedure has a number of benefits. In particular, liver transplantation is expected to reintroduce most of the body's requirements for AGT, already in the correct cell and intracellular com- 
partment [40]. Few other forms of ERT can make these claims. Since the mid-1980s, over 200 liver transplantations have been carried out in $\mathrm{PH} 1$ patients throughout the world [41, 42]. Because most patients were in renal failure at the time, most procedures have been combined liver-kidney transplantations. Evidence to date is that liver transplantation works. It is able to correct the metabolic defects (i.e. elevated oxalate and glycolate synthesis and excretion) [43-46] and reverse at least some of the pathological consequences of chronic $\mathrm{CaOx}$ deposition throughout the body [47]. Rapid metabolic normalization is demonstrated by the immediate return to normal of urinary glycolate levels. However, oxalate excretion usually takes much longer to normalise due to the resolubilization of $\mathrm{CaOx}$ deposited throughout the body during periods of poor renal function or dialysis.

\section{Gene Therapy}

As with most genetic diseases, characterization of the dysfunctional gene allows the possibility of gene therapy. Although the relative benefits of different gene therapy strategies in PH1 have been discussed [48], none have yet to be put into practice. One of the potential problems highlighted very early on was the particular need to be able to transduce a large percentage of the patient's hepatocytes with the normal AGT gene, rather than maximising the total amount of AGT expressed in the organ as a whole. This is because, unlike many other hereditary metabolic diseases, PH1 is a disease of overproduction (of oxalate) not of failure to degrade (as is the case in other metabolic disease such as the lysosomal storage disorders). Any hepatocytes not expressing AGT will continue to synthesise oxalate excessively, irrespective of what its neighbours are doing. AGT overproduction in one hepatocyte cannot compensate for underproduction in its neighbour. Thus a large percentage of hepatocytes need to be transduced with the normal AGT gene. Although no PH1 patients have received gene therapy to date, it remains a viable proposition for the future once better (i.e. more efficient) vectors have been designed.

\section{Chemical Chaperones}

It is increasingly being realised that many, possibly most, missense mutations in human genetic disease cause their effects by decreasing protein stability. This can disturb protein folding and oligomerization, leading to a multitude of downstream effects, such as aggregation, accelerated degradation and mistargeting [49]. Several studies have shown that if the destabilizing effects of mutations can be overcome, then the resulting protein re-ac- quires its functional activity. One of the best examples of this is the $\Delta F 508$ mutation in the CFTR gene that is the prime cause of cystic fibrosis. This mutation destabilises the protein so that it aggregates in the endoplasmic reticulum from which at least some is re-exported back out into the cytosol for degradation by the proteosomes. Very little reaches its normal destination in the plasma membrane. But that which does appears to work fairly normally. Treatments which non-specifically stabilise proteins, such as lowering temperature or addition of osmolytes, such as glycerol, enable the CFTR protein to fold properly. This prevents aggregation in the ER, so that the protein can make its way to the plasma membrane unhindered where it is functionally active [50-52].

In this respect, $\mathrm{PH} 1$ is like other genetic diseases. Many of the missense mutations in the $A G X T$ gene are predicted to decrease the stability of AGT and, therefore, stabilizing agents should correct the aberrant enzyme phenotypes. Formal proof in principle has been obtained for the Pro11Leu+Gly170Arg and Pro11Leu+Ile244Thr polymorphism-mutation combinations, which lead to peroxisome-to-mitochondrion mistargeting, and aggregation/accelerated degradation, respectively. In the case of the former, various treatments known to stabilise proteins non-specifically, such as decreasing the temperature or the addition of glycerol, can normalise AGT targeting in vitro [34]. In the case of the latter, glycerol, betaine, and other non-specific chemical chaperones, have been shown to prevent aggregation, also in vitro [27].

It is likely that such treatments would also do the same for at least some other, but certainly not all, missense mutations (table 1). For example, although they would probably also work for AGT containing the Ser205Pro mutation, they are unlikely to work for missense mutations that cause their effects for reasons unrelated to protein stability, such as Gly82Glu (see above). Another possible example of where protein stabilising agents would not be expected to work is in the case of the Gly41Arg mutation. This mutation leads to AGT destabilization, but it does so by preventing AGT dimerization allowing the protein monomer to aggregate in the peroxisomes and be prematurely degraded. The basic problem (i.e. the presence of the large arginine side-chain preventing apposition of the dimerization interfaces) would be unlikely to be affected by the presence of chemical stabilization agents. Also it is clear that nonsense mutations, insertions, deletions and splice-site mutations would not be open to this approach, because the coding for the correct polypeptide does not exist. This rules out, for example, the second most common mutation 33_34insC. 
Although the common Pro11Leu polymorphism is a component of 'normal' AGT, albeit that encoded by the polymorphic minor $A G X T$ allele, it might be a better target for chemical chaperones that any of the PH1-specific mutations. There is no doubt that it has a more marked phenotype than does either of the most common mutations it segregates and functionally interacts with. Thus, whereas Gly170Arg and Ile244Thr appear to cause AGT no adverse effects when present on their own, Pro11Leu on its own decreases specific catalytic activity, slows down the rate of dimerization, especially at high temperatures, and generates an N-terminal mitochondrial targeting sequence that directs about $5 \%$ of the polypeptide to the mitochondria. In addition, Pro1 1 Leu appears to sensitise AGT to the untoward effects of several other PH1-specific mutations, including Gly170Arg and Ile244Thr (see above). Directing the design of chemical chaperones against the effects of the Pro11Leu polymorphism has the advantage that it would catch all the mutations that segregate and functionally interact with it.

There is another consideration that might make the use of Pro11Leu as the principal target for chemical chaperones even more important. It has been speculated previously that Pro1 1Leu might have a role to play in determining an individual's susceptibility to idiopathic calcium oxalate kidney stone disease [53]. However, the suggested relationship is not simple, as it is diet dependent. It has been suggested that Pro11Leu is more likely to be beneficial (i.e. decrease the chances of $\mathrm{CaOx}$ kidney stones) in individuals whose diets are high in meat, and is more likely to be disadvantageous (i.e. increase the chances of $\mathrm{CaOx}$ kidney stones) in those whose diets are low in meat (e.g. vegetarians). Compatible with this suggestion is the recent finding that the frequency of the Pro11Leu polymorphism is much higher in populations in which the ancestral diet is extremely meat-rich than it is in those in which the ancestral diet is more mixed or more vegetarian [53]. The use of anti-Pro11Leu chemical chaperones in the general populations could be a twoedged sword. It could decrease the susceptibility to $\mathrm{CaOx}$ stones in individuals carrying the polymorphism who were vegetarian, but increase it in those that ate a lot of meat. The likely success, or otherwise, of chemical chaperones in being able to counteract the effects of the specific mutations and polymorphisms discussed above is summarized in table 1 .

Whatever the best target for chemical chaperones is, it is clear that extensive work will be required to find small molecules that bind to and stabilise AGT with a much greater affinity than the agents used so far. In the long run, it will be worth it because not only will it lead to enormous improvements in the treatment of a potentially life-threatening disease that is otherwise difficult to treat, but also because such an agent might have wider benefits as a prophylactic against $\mathrm{CaOx}$ stone disease in general.

\section{References}

1 Danpure CJ, Jennings PR: Peroxisomal alanine:glyoxylate aminotransferase deficiency in primary hyperoxaluria type I. FEBS Lett 1986; 201:20-24.

2 Danpure CJ: Primary hyperoxaluria; in Scriver CR, Beaudet AL, Sly WS, Valle D, Childs B, Kinzler KW, Vogelstein B (eds): The Metabolic and Molecular Bases of Inherited Disease. New York, McGraw-Hill, 2001, vol II, pp 3323-3367.

-3 Danpure CJ, Rumsby G: Molecular aetiology of primary hyperoxaluria and its implications for clinical management. Expert Rev Mol Med 2004;6:1-16.

-4 Danpure CJ, Jennings PR, Fryer P, Purdue PE, Allsop J: Primary hyperoxaluria type 1: genotypic and phenotypic heterogeneity. J Inherit Metab Dis 1994; 17:487-499.

5 Lumb MJ, Danpure CJ: Functional synergism between the most common polymorphism in human alanine:glyoxylate aminotransferase and four of the most common disease-causing mutations. J Biol Chem 2000;275:3641536422 .
-6 Danpure CJ, Cooper PJ, Wise PJ, Jennings PR: An enzyme trafficking defect in two patients with primary hyperoxaluria type 1 : peroxisomal alanine/glyoxylate aminotransferase rerouted to mitochondria. J Cell Biol 1989; 108:1345-1352

7 Danpure CJ, Purdue PE, Fryer P, Griffiths S, Allsop J, Lumb MJ, Guttridge KM, Jennings PR, Scheinman JI, Mauer SM, Davidson NO: Enzymological and mutational analysis of a complex primary hyperoxaluria type 1 phenotype involving alanine:glyoxylate aminotransferase peroxisome-to-mitochondrion mistargeting and intraperoxisomal aggregation. Am J Hum Genet 1993;53:417-432.

-8 Takada Y, Kaneko N, Esumi H, Purdue PE, Danpure CJ: Human peroxisomal $L$-alanine: glyoxylate aminotransferase: evolutionary loss of a mitochondrial targeting signal by point mutation of the initiation codon. Biochem J 1990;268:517-520.

$>9$ Zhang X, Roe SM, Hou Y, Bartlam M, Rao Z, Pearl LH, Danpure CJ: Crystal structure of alanine:glyoxylate aminotransferase and the relationship between genotype and enzymatic phenotype in primary hyperoxaluria type 1 . J Mol Biol 2003;331:643-652.

-10 Motley A, Lumb MJ, Oatey PB, Jennings PR, De Zoysa PA, Wanders RJ, Tabak HF, Danpure CJ: Mammalian alanine:glyoxylate aminotransferase 1 is imported into peroxisomes via the PTS1 translocation pathway: increased degeneracy and context specificity of the mammalian PTS1 motif and implications for the peroxisome-to-mitochondrion mistargeting of AGT in primary hyperoxaluria type 1 . J Cell Biol 1995;131:95-109.

11 Huber PAJ, Birdsey GM, Lumb MJ, Perkins TJ, Prowse DTR, Knight DR, Danpure CJ: Peroxisomal import of human alanine: glyoxylate aminotransferase requires ancillary targeting information remote from its C-terminus. J Biol Chem 2005, in press. DOI: 10.1074/jbc.M502719200.

12 Purdue PE, Lumb MJ, Fox M, Griffo G, Hamon Benais C, Povey S, Danpure CJ: Characterization and chromosomal mapping of a genomic clone encoding human alanine:glyoxylate aminotransferase. Genomics 1991;10:34-42. 
13 Purdue PE, Takada Y, Danpure CJ: Identification of mutations associated with peroxisometo- mitochondrion mistargeting of alanine/glyoxylate aminotransferase in primary hyperoxaluria type 1. J Cell Biol 1990;111:23412351.

14 Purdue PE, Lumb MJ, Allsop J, Danpure CJ: An intronic duplication in the alanine:glyoxylate aminotransferase gene facilitates identification of mutations in compound heterozygote patients with primary hyperoxaluria type 1 . Hum Genet 1991;87:394-396.

15 Coulter-Mackie MB, Rumsby G: Genetic heterogeneity in primary hyperoxaluria type 1 : impact on diagnosis. Mol Genet Metab 2004; 83:38-46.

16 Leiper JM, Oatey PB, Danpure CJ: Inhibition of alanine:glyoxylate aminotransferase dimerization is a pre-requisite for its peroxisome-tomitochondrion mistargeting in primary hyperoxaluria type 1. J Cell Biol 1996;135:939951.

17 Purdue PE, Allsop J, Isaya G, Rosenberg LE, Danpure CJ: Mistargeting of peroxisomal Lalanine:glyoxylate aminotransferase to mitochondria in primary hyperoxaluria patients depends upon activation of a cryptic mitochondrial targeting sequence by a point mutation. Proc Natl Acad Sci USA 1991;88:1090010904.

18 Lumb MJ, Drake AF, Danpure CJ: Effect of $\mathrm{N}$-terminal alpha helix formation on the dimerization and intracellular targeting of alanine:glyoxylate aminotransferase. J Biol Chem 1999;274:20587-20596.

19 McNew JA, Goodman JM: An oligomeric protein is imported into peroxisomes in vivo. $\mathrm{J}$ Cell Biol 1994;127:1245-1257.

-20 Glover JR, Andrews DW, Rachubinski RA: Saccharomyces cerevisiae peroxisomal thiolase is imported as a dimer. Proc Natl Acad Sci USA 1994;91:10541-10545.

21 Chen WJ, Douglas MG: The role of protein structure in the mitochondrial import pathway: analysis of the soluble F1-ATPase betasubunit precursor. J Biol Chem 1987;262: 15598-15604.

22 Eilers M, Schatz G: Protein unfolding and the energetics of protein translocation across biological membranes. Cell 1988;52:481-483.

-23 Abe Y, Shodai T, Muto T, Mihara K, Torii H, Nishikawa S, Endo T, Kohda D: Structural basis of presequence recognition by the mitochondrial protein import receptor Tom20. Cell 2000; 100:551-560.

-24 Muto T, Obita T, Abe Y, Shodai T, Endo T, Kohda D: NMR identification of the Tom 20 binding segment in mitochondrial presequences. J Mol Biol 2001;306:137-143.

25 Oatey PB, Lumb MJ, Danpure CJ: Molecular basis of the variable mitochondrial and peroxisomal localisation of alanine:glyoxylate aminotransferase. Eur J Biochem 1996;241:374385.

26 von Schnakenburg C, Rumsby G: Primary hyperoxaluria type 1: a cluster of new mutations in exon 7 of the AGXT gene. J Med Genet 1997;34:489-492.
27 Santana A, Salido E, Torres A, Shapiro LJ: Primary hyperoxaluria type 1 in the Canary Islands: a conformational disease due to I244T mutation in the P11L-containing alanine:glyoxylate aminotransferase. Proc Natl Acad Sci USA 2003;100:7277-7282.

28 Purdue PE, Lumb MJ, Allsop J, Minatogawa Y, Danpure CJ: A glycine-to-glutamate substitution abolishes alanine:glyoxylate aminotransferase catalytic activity in a subset of patients with primary hyperoxaluria type 1 . Genomics 1992;13:215-218.

29 Pirulli D, Puzzer D, Ferri L, Crovella S, Amoroso A, Ferrettini C, Marangella M, Mazzola G, Florian F: Molecular analysis of hyperoxaluria type 1 in Italian patients reveals eight new mutations in the alanine:glyoxylate aminotransferase gene. Hum Genet 1999; 104:523525.

30 Nishiyama K, Funai T, Katafuchi R, Hattori F, Onoyama K, Ichiyama A: Primary hyperoxaluria type I due to a point mutation of $\mathrm{T}$ to $\mathrm{C}$ in the coding region of the serine:pyruvate aminotransferase gene. Biochem Biophys Res Commun 1991;176:1093-1099.

31 Nishiyama K, Funai T, Yokota S, Ichiyama A: ATP-dependent degradation of a mutant serine:pyruvate/alanine:glyoxylate aminotransferase in a primary hyperoxaluria type 1 case. J Cell Biol 1993;123:1237-1248.

32 Danpure CJ: Molecular and clinical heterogeneity in primary hyperoxaluria type 1 . Am J Kidney Dis 1991;17:366-369.

33 Monico CG, Rosetti S, Olson JB, Milliner DS: Pyridoxine effect in type 1 primary hyperoxaluria is associated with the commonest mutant allele. Kidney Int 2005;67:1704-1709.

34 Lumb MJ, Birdsey GM, Danpure CJ: Correction of an enzyme trafficking defect in hereditary kidney stone disease in vitro. Biochem J 2003;374:79-87.

35 Takada Y, Mori T, Noguchi T: The effect of vitamin B6 deficiency on alanine:glyoxylate aminotransferase isoenzymes in rat liver. Arch Biochem Biophys 1984;229:1-6.

36 Beutler E, Grabowski GA: Gaucher disease; in Scriver CR, Beaudet AL, Valle D, Sly WS (eds): The Metabolic and Molecular Bases of Inherited Disease. New York, McGraw-Hill, 2001, pp 3635-3668.

37 Kamoda N, Minatogawa Y, Nakamura M, Nakanishi J, Okuno E, Kido R: The organ distribution of human alanine-2-oxoglutarate aminotransferase and alanine-glyoxylate aminotransferase. Biochem Med 1980;23:25-34.

38 Cooper PJ, Danpure CJ, Wise PJ, Guttridge KM: Immunocytochemical localization of human hepatic alanine:glyoxylate aminotransferase in control subjects and patients with primary hyperoxaluria type 1 . J Histochem Cytochem 1988;36:1285-1294.

39 Yokota S, Oda T, Ichiyama A: Immunocytochemical localization of serine: pyruvate aminotransferase in peroxisomes of the human liver parenchymal cells. Histochemistry 1987; 87:601-606.

40 Danpure CJ: Scientific rationale for hepatorenal transplantation in primary hyperoxaluria type 1; in Touraine JL (ed): Transplantation and Clinical Immunology. Amsterdam, Excerpta Medica, 1991, vol 22, pp 91-98.

41 Jamieson NV: European PH1 transplant registry report on the results of combined liver/kidney transplantation for primary hyperoxaluria 1984 to 1992. European PHI Transplantation Study Group. Transplant Proc 1995;27:12341236.

42 Jamieson NV: The results of combined liver/ kidney transplantation for primary hyperoxaluria (PH1) 1984-1997. The European PH1 transplant registry report. J Nephrol 1998;11 (S-1):36-41.

43 Watts RW, Calne RY, Rolles K, Danpure CJ, Morgan SH, Mansell MA, Williams R, Purkiss P: Successful treatment of primary hyperoxaluria type I by combined hepatic and renal transplantation. Lancet 1987;ii:474-475.

$\checkmark 44$ Cochat P, Faure JL, Divry P, Danpure CJ, Des$\cos$ B, Wright C, Takvorian P, Floret D: Liver transplantation in primary hyperoxaluria type 1. Lancet 1989;i:1142-1143.

$\checkmark 45$ de Pauw L, Gelin M, Danpure CJ, Vereerstraeten P, Adler M, Abramowicz D, Toussaint C: Combined liver-kidney transplantation in primary hyperoxaluria type 1 . Transplantation 1990;50:886-887.

46 Watts RW, Danpure CJ, de Pauw L, Toussaint: Combined liver-kidney and isolated liver transplantations for primary hyperoxaluria type 1: the European experience. The European Study Group on Transplantation in Hyperoxaluria Type 1. Nephrol Dial Transplant 1991;6:502-511.

47 McDonald JC, Landreneau MD, Rohr MS, DeVault GAJ: Reversal by liver transplantation of the complications of primary hyperoxaluria as well as the metabolic defect. N Engl J Med 1989;321:1100-1103.

48 Danpure CJ: Advances in the enzymology and molecular genetics of primary hyperoxaluria type 1: prospects for gene therapy. Nephrol Dial Transplant 1995;10(suppl 8):24-29.

49 Morello JP, Petaja-Repo UE, Bichet DG, Bouvier M: Pharmacological chaperones: a new twist on receptor folding. Trends Pharmacol Sci 2000;21:466-469.

-50 Denning GM, Anderson MP, Amara JF, Marshall J, Smith AE, Welsh MJ: Processing of mutant cystic fibrosis transmembrane conductance regulator is temperature-sensitive. Nature 1992;358:761-764.

51 Brown CR, Hong-Brown LQ, Biwersi J, Verkman AS, Welch WJ: Chemical chaperones correct the mutant phenotype of the delta F508 cystic fibrosis transmembrane conductance regulator protein. Cell Stress Chaperones 1996; 1:117-125.

-52 Sato S, Ward CL, Krouse ME, Wine JJ, Kopito RR: Glycerol reverses the misfolding phenotype of the most common cystic fibrosis mutation. J Biol Chem 1996;271:635-638.

53 Caldwell EF, Mayor LR, Thomas MG, Danpure CJ: Diet and the frequency of the alanine: glyoxylate aminotransferase Pro11Leu polymorphism in different human populations. Hum Genet 2004;115:504-509. 